\title{
SCIENTIFIC PROGRESS AND POSTMODERN CULTURE: THE AFRICAN EXPERIENCE
}

\author{
Isaiah NEGEDU, $\mathrm{PhD}$ \\ Department of Philosophy, \\ Federal University Lafia, Nasarawa State
}

\begin{abstract}
Scientific discourse grew out of various philosophical puzzles raised by human beings from the period of antiquity; and each age always comes with a renewed vigor for development over previous schools of thought with their attendant theories. With the speed of scientific progress and scientific awareness, there is no doubt that scholars from various disciplines fashion out theories to meet with the demands of the scientific spirit. It is this very presence of the scientific society that leads to contest for relevance among various theories/schools of thought. The African situation has been quite unique as the development of science is greeted with the idea that scientific developments have moral boundaries. Critically looking at development in science and how it has tailored our outlook in contemporary times, we opine that scientific investigations into phenomena make philosophical debates more relevant in our modern world.

Keywords: Science, Scientific Progress, Post Modernity, Dialectic, Culture, African Experience.
\end{abstract}

\section{Introduction}

The main characteristic that preoccupies every debate both in the realm of scholarship and informal discourse has been the place of man in the universe and how to solve the problems of the human person. Thus, humanism has been a prevalent theme associated with the second half of the $20^{\text {th }}$ century down through the $21^{\text {st }}$ century. The tone of the criticism leveled against scholarship during the classical times gives an insight into the escapist attitude of philosophers from the social strife of man, which was preoccupied by a journey into changeless reality. Though the existence of science dates back almost immediately to the classical age, there was less freedom of thought that enables man to explore various possibilities. The reason for this attitude was either because it would change the course of history physically, or the fear that people will be induced to change their mental orientation into various belief systems. Science did not to exist to serve as a threat to various schools of thought but to search for meeting points of disciplines that gives more worth to the human person.

Classical philosophy largely favors the African system with its emphasis on the preservation of tradition; hence the slow pace of radical scientific movements. But even post-modern thinking is quite impressive in the sense that 
it was not built in isolation, at least, there was a foundation and such foundations made it necessary to see the errors inherent in classical thought. Why should discourse on the freedom of thought be necessary, but for the fact that there was an intention to subsume the freedom of man into a system. It is with this same spirit of appreciation of post-modern thought through the lens of classical thinking, that scientific progress in Africa should be seen through the lens of African tradition.

\section{Evolution of Scientific Progress}

The etymological meaning of science suggests that it is a peculiar form of knowledge with wide applications. One of the characteristics of science therefore is its ability to embrace other disciplines other than the experimental sciences. As a form of knowledge, its application in classical antiquity was primarily within the domain of philosophy. Thus, scientific development without recourse to its root would amount to sterile scholarship. It is in this regard that every form of scientific discipline, particularly of the experimental sciences employs the critical-analytic method to arrive at solutions to problems. However, the distinctive mark between the former applications of science from the post modern age was the limiting of science when there is perceived threat to the meta-empirical world. The reason science is considered as a reactionary discipline is not necessarily because it denies the existence of the supernatural realm, but its insistence on the negligence of that realm and total focus on the natural world if man is going to encounter progress from one generation to another. This appears to be an extreme borne out of the hate of metaphysics. The implications of this view is even more for the experimental sciences than for any other discipline because the tentativeness of solutions in scientific advancement is more pronounced that it has become a feature of science.

This has rightly influenced the history of science to be the replacement of false theories by theories that are considered to be true. Scientific revolutions at the dawn of the modern period were fundamental to the extent that scholarship before the $15^{\text {th }}$ century was seen to be pre-scientific. By and large, the various revolutions in science has shown that progress in science could be gradual and incremental or radically discontinuous. The various theories of evolution of scientific theories fall within these two categories. Those who uphold the notion of scientific advancement as radically discontinuous opine that past theories that are not workable for the current age should be absolutely detached from current scientific notions of progress that produce tentative results. Scientific progress, advancement, development or whatever its appellation may be, is only possible because there is always an existing structure on ground that is unfavorable for scholarship. As a result of the self-critical attitude of science therefore, theories are replaced with old ones. According to Larry Laudan: 


\begin{abstract}
...it is vividly clear that the views of the scientific community about how to test theories and about what counts as evidence have changed dramatically through history... The fact that the evaluative strategies of scientists of earlier eras are different from our strategies makes it quixotic to suppose that we can access the rationality of their science by ignoring completely their views about how theories should be evaluated. $(1996,80)$
\end{abstract}

An insistence on the history of scientific progress without reference to flawed theories that gave birth to current theories is a contradiction in terms because gradual progressiveness necessarily implies the presence of existing structures. That is why John Losee opines that "a progressive sequence is constituted by stages each of which is superior to its predecessor" $(2004,7)$. Thus, scientific advancement cannot be associated only with descriptive progress. Descriptiveness alone does not produce the self critical attitude needed in science; hence the relevance of theoretical progress. That is why theories must be fashioned to determine how man could better live in the world.

It is this very notion of uncertainty that makes scientific investigations unending. Karl Popper succinctly noted it when he said: "The game of science is, in principle, without end. He who decides one day that scientific statements do not call for any further test and that they can be regarded as finally verified, retires from the game" $(1992,32)$. Pyotr Fedoseyev aptly stated that our age is primarily concerned with the importance of philosophy of science towards analyzing the role of scientific and technical progress in the life of man and society in general. Knowledge in general has always returned to man, so that on the final analysis, even the science of metaphysics which has undergone several negative criticisms is studied in order to teach man how to live in the world $(1989,3)$. Natural scientists have always considered the solutions of the problems of man to be the primary aim of science. Thus, scientific progressiveness is more often characterized by its ability to set goals and to a large extent make those goals achievable. The result of science has a more radically immanent application "... the aim of science is to secure theories with a high problem-solving effectiveness" (LAUDAN 1996, 77). The dividends of this goal of science are worth-noting; it takes into account scientific progress as it was in the past in line with its futuristic value. It also assures goals that have immanent bearing thereby bringing it closer to epistemic access (LAUDAN 1996, 78).

\title{
The Logic of Science
}

Science has its own progressive tool of reasoning. Historical developments in scholarship show that it uses a method of analysis and synthesis to arrive at its results. The validation of scientific inquiry lies primarily within its logic. That is 
why the scientist is that scholar who is always guided by the accepted rules of logical reasoning. To be competent as a scientist therefore, one should be competent in logical reasoning; it is a methodical reasoning that the scientific method should employ. When viewed holistically, the logic of science takes the Hegelian dialectical pattern of a thesis-antithesis-synthesis. It is a continuous process, though not routinely applied because of its accommodation of alternative possibilities. What guarantees alternative possibilities is the very fact of the theory of probability that sustains science.

Probability as a theory does not guarantee outright certainty, but its nearness to precision and or truth is highly probable than doubt. But the method of science is not completely inferential in its probable form; no matter how plausible our reasoning process may be, in the midst of various analogies, we creatively employ deductive reasoning. Whether plausible reasoning is limited to laboratory experimentation is another issue for determination. However, even the untrained mind through creative reasoning uses logic in commonsensical experiences. Scientific knowledge combines both the principles of experimental and theoretical reasoning to arrive at a method that takes all disciplines into cognizance. The scientific society cannot therefore be devoid of method. Methodology in this regard deals with the principles of the organization of knowledge and each science has special demands on organization.

\section{Post Modernity}

Post modernity is generally associated with an economic, cultural or scientific condition of society which comes almost immediately after modernity. From the philosophical perspective, post modernity marks the end of modernity. When viewed from the angle of any discipline, it represents a gradual movement that comes to play through some form of creative dialectic and it is marked by continuity. It emerged as a response to some perceived problems posed by modernity.

Philosophers from the period of antiquity viewed nature from a unitary perspective that was supernal in its own right. The human person and all metaempirical forces were regarded as part of nature thereby setting the rules of conduct for man. Its implication for the society at such moment was that reason was determined or curtailed by nature; the human person and all suprasensible beings were made for nature and not the other way round. Man in this sense was not free to explicate nature wholly for its exploitation. The Judeo-Christian conception of God gradually eroded the concept of logos as proffered by the classical scholars. It would not have been possible for the creator of the world to be fully involved with nature in human terms. This pantheistic view of God was replaced with the monotheistic concept. By embracing God, humans could attain universal truth. This Thomistic view of world order was a defining moment for 
science as it raised relevant questions and objections. These objections were due in part to the fact that empirical investigations into the natural world order had some results that were contrary to certain divine revelations. The most prominent was the Copernican revolution by Nicholas Copernicus: “... which held that the earth moved around the sun in contradiction to several passages in the scriptures that referred to the earth as unmoving" (PARFITT 2002, 14). Prior to Copernicus' scientific investigations, Ockham had earlier denied that human beings could have access to God's universal truths through scientific experimentation: “... since God was all-powerful he was not limited by human rationality or by nature, which were merely particular creations among the infinity of creativity of which God was capable" (PARFITT 2002, 14). This therefore puts the foundation of human knowledge into question. The emergence of modern science paved way for the molding of nature in accord with human needs. Decrease in proximity of divine cause or element meant a conscious awareness and nearness of people in the ability of science to improve the wellbeing of man.

Another important element in the emergence of modernity was the change in the perception that man was entirely part of nature; it gave way for the concept of the autonomy of the free individual. The human person was not engulfed in nature in a communal stat to the extent of losing his individuality. However, modernity still had some deficiencies that slowed its growth toward science; it was replete with the legitimizing of science in the direction of conformed dialectic that bothered itself with a meta-discourse. Thus, postmodernity is largely: "...a reaction against these central elements of modernity, particularly metatheory, foundationalism and subject-object relations... wherein the subject is allocated an all-powerful position in relation to the object" (PARFITT 2002, 21).

Evolutionary biology with Darwin as its major proponent greatly influenced this shift from modern to post modern outlook of the world. The influence of biology changed the whole concept of life. It postulates that wherever there is life, there is also activity, there is action. For life to persist, these activities and behavior that are part of life should be constantly adjusted to suit the environment. There ceases to be blind conformity to existential realities. There is room for debates and dialogue that keeps life moving progressively. Darwin therefore formulated a version of evolution that undergoes modification through variation and natural selection. It laid the foundation which a naturalistic approach to the theory of knowledge should take. The insistence on naturalistic approach to things was not an express denial of any supernatural influence on the world, but a reaction against speculated questions without attempt to relate such issues to observational evidence (LEWENS 2007, 191). In line with this theory, scientific progress was viewed from the evolutionary perspective "...within 
which natural selection operates on a set of conceptual variants such that the fittest variants survive" (LOSEE 2004, 141).

Lyotard who is credited with the emergence of the idea of postmodernism opines that knowledge does not legitimizes itself without room for academic debates that justifies its proof (BENHABIB 1984, 119). He sees the concept of post-modernity as very critical in the development of the world and scientific progress. Thus accordingly, Jean-Francois Lyotard opined: "post modernism refines our sensitivity to differences and reinforces our ability to tolerate the incommensurable. Its principle is not the expert's homology, but the inventor's paralogy" (1984, xxv). By this, post modernism encourages a knowledge-based approach that is radically discontinuous from classical knowledge that has its foundation on meta-narratives. But meta-narratives are not altogether unscientific, since classical thought is not entirely devoid of the inventor's paralogy, though to some extent, it was detached from practical human condition.

\section{Toward a Synthetic Analysis}

The dialectics of post modern culture always moves in the direction of scientific development. Most times, we tend to think that science precedes post modernity in terms of technological progress. While the notion of scientific development is incontestable, attitude of various disciplines towards such movement is an entirely unique issue. The gradual unfolding of post modern thought necessarily entails that its primary aim is to ensure that it goes in line with the scientific spirit. It means that in all facets of development notwithstanding the discourse involved, there should not be a dialectical reversal into traditionalism. Historical development has shown that to some extent, science has enjoyed an unguarded freedom, which has led to placement of less value on the moral worth of scientific research. This brings into question the supposed intention of science to take the human person into consideration in its development. If reactions to classical and modern thoughts by post modernity were because scholarship in former times took an escapist route from the existential conditions of man, then scholarship in current times should be primarily concerned with the enhancement of the dignity of man. But history has shown that their development proceeds in quite a contradictory way; quite often, they have not discovered the truth so much as distorted and concealed it "...the achievements of the natural sciences were to a great extent used against humanity, particularly in the destructive wars of the $20^{\text {th }}$ century" (FEDOSEYEV 1989, 4). It is this very problem of the moral worth of scientific progress that takes the ontological dimension that bothers on philosophy. What makes various disciplines including science scientific is not because of the provision of experimental data for observation in the laboratory, but because of that critical analytic attitude that philosophy provides. Some of the 
problems inherent in science is because of the refusal of science to take some of its issues to the philosophical level. The interaction of philosophy as a world outlook and as a method of scientific knowledge can only progress when the dogmatism inherent in each discipline is loosened. "...the manifestations of dogmatism and authoritarianism are still felt to this day. This is why the philosophical comprehension of the changes taking place in modern natural science should become a school for a new, dialectical creative thinking" (FEDOSEYEV 1989, 9).

For science to meet the needs of man in the society it has to be used as a force of socio-cultural engineering otherwise scientism which sees science as the beginning and end of all that exists in the universe is deified. Though scientific knowledge strictly speaking is capable of solving most of human problems, the deification of science has been antithetical to human progress. Uncontrolled scientific progress has more implications even for science than for any other discipline. This is because the very chain of thought which scientism intends to discard carries with it some of the logical foundations of scientific knowledge. On the other hand, antiscientism which is an outright rejection of science also tends towards negation of human progress. We cannot trust the future of the world into some supernal principles without regard for naturalism. There is a meeting point between scientism and antiscientism, and it is to the effect that both schools of thought negate scientific knowledge for the benefit of man. Any attempt to enthrone either naturalism or supernaturalism is injurious as it places little value on human existence. While scientism has been responsible for the destruction of lives and properties through the invention of atomic bombs which have been used in various world wars and civil unrest in different societies, antiscientism has been used in different historical periods by various religious sects to enthrone the suprasensible world through a God-centered religion that sees the world as a divine arrangement thereby destroying all forces that are perceived to oppose such arrangement. Ironically, both schools of thought are one-directional in their thinking leaving no room for alternative possibilities. Any appeal to enchantment or disenchantment in its negative form that leads to antiscientism or scientism as the case may be, is a total disconnect from the goal and end of science. Such ideologies are nothing but a complete replication of Popper's closed society and it defies human freedom.

We must aptly note that some parts of Africa are very slow in keying into the vision of scientific progress. In Nigeria for instance, there has been decrease in government investment in scientific research over the years, which gradually demeans the communal status of inquiry and scientific research. Its implication for the society is that research is largely an affair of the individual. Scientific research by its nature must be social, lest it ceases to be scientific. You cannot insist indirectly that education (research) is a private business and expect a social 
or communal outcome. Notwithstanding the errors that may be inherent in postmodernity, its relevance is seen in its forward movement into the future, the fact that we can only think of progress that is made possible through a critical dialectic of change.

\section{Conclusion}

It is clear from our analysis that we cannot speak of the separation of scientific society and postmodern culture. These two concepts move in a progressive direction through systematic dialectic; hence they become mutually inclusive. Culture is inherently dynamic and this brings to question the static nature of African tradition, since to have a culture is to embrace change. Postmodernism on its own is a culture since it insists on critical reflections on previous schools of thought. It would be a reversal to demand that post-modern culture should catch up with the static nature of African tradition. A primary element that is needed to increase the credibility of our thought system is to embrace the element of selfcriticism that steps up the debate from a primitive level to an objective state. In this sense, even values could be subject to debate so as to arrive to a more holistic approach to life situations and not merely subjecting it to the relativeness of ethics, where every society has its own definition of concepts without a point of compromise.

\section{Relevant Literature}

1. BENHABIB, Seyla. "Epistemologies of Postmodernism: A Rejoinder", [New German Critique], pp103-126., 1984. No 33. Accessed November 29, 2014. Web.

2. ETIEYIBO, Edwin. "Post-Modern Thinking and African Philosophy", [Filosofia Theoretica: Journal of African Philosophy, Culture and Religions], pp67-82. Vol 3. No 1. 2014. Paperback.

3. FEDOSEYEV, Pyotr. "Philosophy, Science and Man", [Studies in Logic and the Foundations of Mathematics, Barwise, J. et al, Eds.,], pp3-25, 1989. Vol 126. Elsevier Science Publishers: Amsterdam, 3- Paperback. 
4. LAUDAN, Larry. [Beyond Positivism and Relativism], 1996. Westview Press Inc: Colorado. Paperback.

5. LEWENS, Tim. [Darwin], 2007. Routledge: London. Paperback.

6. LOSEE, John. [Theories of Scientific Progress. An Introduction], 2004. Routledge: London. Paperback.

7. LYOTARD, J. F. [The Postmodern Condition], 1984. University of Minnesota: Minneapolis. Paperback.

8. PARFITT, Trevor. [The End of Development? Modernity, PostModernity and Development], 2002. Pluto Press: London. Paperback.

9. POPPER, Karl. [The Logic of Scientific Discovery], 1992. Routledge: London. Paperback. 